\title{
Knowledge, Awareness and Attitude Towards Predisposing Factors to Diabetes Mellitus Among General Population in Chennai
}

\author{
Rajasri Pradeep ${ }^{1}$, M. P. Brundha² and VB Preejitha ${ }^{3}$ \\ ${ }^{1}$ Department of Pathology Saveetha Dental College, Saveetha Institute of Medical \\ and Technical Sciences, Saveetha University, India \\ ${ }^{2}$ Associate professor, Department of Pathology Saveetha Dental College, Saveetha Institute of Medical and \\ Technical Sciences, Saveetha University, 162, Poonamallee High Road, Chennai-600077, Tamil Nadu, India. \\ ${ }^{3}$ Tutor Department of Pathology Saveetha Dental College and Hospitals Saveetha Institute of Medical and \\ Technical Sciences, Saveetha University, Chennai-600077, Tamil Nadu, India
}

\section{ABSTRACT}

Diabetes mellitus is a disorder or chronic illness which can lead to premature death and significant disability . It is an epidemic and therefore the risk or problems associated with this disorder can be minimised by early diagnosis and management. Diabetes is characterised by hyperglycemia which is caused due to lack of insulin secretion , improper insulin action or both. There are a lot of causative disorders and diseases that can lead to diabetes but diabetes is also one such causative disorder as it alone can pave way for other diseases. Hypertension, obesity, periodontitis and other dental problems , congestive heart failure to name a few are diseases that arise due to diabetes. In a nutshell, diabetes is a two way boat which can be caused by other diseases/disorders or cause other diseases/disorders. To vary what we eat and how we balance our lifestyle is a necessity.

\section{KEY WORDS: DIABETES MELLITUS, PREDISPOSING FACTOR, AWARENESS.}

\section{INTRODUCTION}

Diabetes mellitus is a disorder or chronic illness which can lead to premature death and significant disability . It is an epidemic and therefore the risk or problems associated with this disorder can be minimised by early diagnosis and management. (Daousi, 2006) Diabetes is characterised by hyperglycemia which is caused due to lack of insulin secretion, improper insulin action or

\section{ARTICLE INFORMATION}

*Corresponding Author: brundha.sdc@saveetha.com Received 26th July 2020 Accepted after revision 19th Sep 2020 Print ISSN: 0974-6455 Online ISSN: 2321-4007 CODEN: BBRCBA

Thomson Reuters ISI Web of Science Clarivate Analytics USA and Crossref Indexed Journal

\section{Clarivate
Analytics}

NAAS Journal Score 2020 (4.31) SJIF: 2020 (7.728)

A Society of Science and Nature Publication,

Bhopal India 2020. All rights reserved.

Online Contents Available at: http//www.bbrc.in/

Doi: http://dx.doi.org/10.21786/bbrc/13.8/117
both.(Kharroubi, 2015)This comes with dysfunction, long term damage and failure of different organs like eyes , kidney, nerves, heart and blood vessels.(Association and American Diabetes Association, 2007) Retinopathy, nephropathy and neuropathy with risk of amputations and foot ulcers are commonly associated with diabetes. Lipoprotein abnormalities and hypertension is also seen. (Amor et al., 2020)(Yari et al., 2020)

According to studies done in the recent past there are millions of adults who are at a very high risk of developing diabetes due to their sedentary lifestyle, age , obesity and genetic factors. (Aynalem and Zeleke, 2018) As the disorder rate is high, it is very much essential for the general population to have awareness on a broad scale for prevention and management.(Zubkova et al., 2019) About $90 \%$ of the population suffering from diabetes are said to have Type 2 . (Mercaldo, Nardone and Santone, 2017)

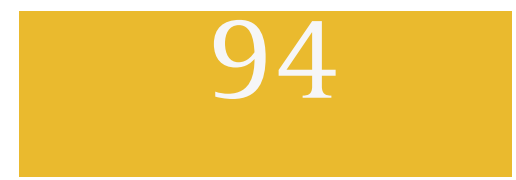


The population for this study was chosen from Chennai city and most of them tested are above the age of 23 . Diabetes mellitus is caused due to multiple factors and can affect even a newborn owing to the genes or the lifestyle maintained by the mother. Therefore strategies of elimination of diabetes mellitus can be done only if the general population have minimum awareness and knowledge. (Asfandiyarova, 2015) Certain studies conclude that around $30 \%$ of the people are not diagnosed.(Buell, Kermah and Davidson, 2007; Mercaldo, Nardone and Santone, 2017) This can lead to death or other major problems . Diabetes is one of the leading causes of death in some countries. (Olefsky, 2001) Certain environmental factors as we discussed earlier are also responsible towards contributing towards the disease.(Hales, Nicholas Hales and Barker, 2001) Not being diagnosed by this disorder is harmful and can eventually lead to death owing to the high glucose content in the body followed by other diseases.(Kyvik and Green, 2008)

This epidemic of diabetes is becoming underway and studies are being done to know if diabetes is becoming the biggest epidemic of the 21st century.('John F. Maher, MD, FACP, FRCP(I) 1929-1992', 1993) The increasing prevalence is mainly seen in obese children and adults and also to those belonging to older age groups. The cardinal characteristic feature of diabetes mellitus is an increase in glucose levels. Insulin resistance is the characteristic metabolic defect of this disorder. This can lead to morbidity and premature mortality (Deshpande, Harris-Hayes and Schootman, 2008) .As we all know, the main treatment for diabetes is increasing insulin content in the body. A huge increase in the insulin levels can lead to a condition called Hyperinsulinemia which is also dangerous.As mentioned earlier, there are a lot of causative disorders and diseases that can lead to diabetes but diabetes is also one such causative disorder as it alone can pave way for other diseases.(Finucane and Popplewell, no date) Hypertension, obesity, periodontitis and other dental problems, congestive heart failure to name a few are diseases that arise due to diabetes. (Williams, 2011) In a nutshell, diabetes is a two way boat which can be caused by other diseases/disorders or cause other diseases/disorders. (Accordino et al., 2020) To vary what we eat and how we balance our lifestyle is a necessity.

\section{MATERIAL AND METHODS}

The study was conducted with the help of a cross sectional questionnaire which was circulated with the help of social media and the internet. The target population were mostly the middle aged people of Chennai. The questionnaire consisted of 20 questions that tested their knowledge, attitude and awareness regarding predisposing factors to diabetes mellitus. The questions consisted of major risk factors commonly seen like obesity, lifestyle, age, alcoholism and smoking habits, hypertension, hyperglycaemia etc.

\section{RESULTS AND DISCUSSION}

Figure 1: Pie chart representing $42 \%$ of the respondents are of the age group 30-40 (Blue), 35\% of the respondents are of the age group 40-50 (Red) while the remaining are of the age group 50-60(Green).

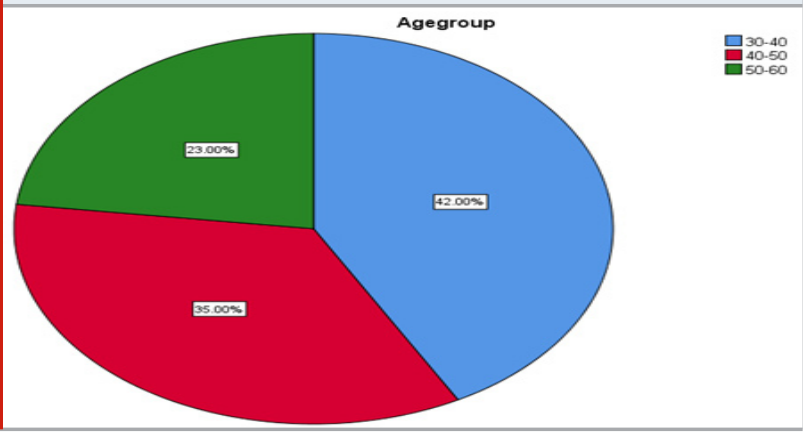

Figure 2: Pie chart representing $69 \%$ of the respondents are Females (Blue) while the remaining $31 \%$ of the respondents are males. (Red)

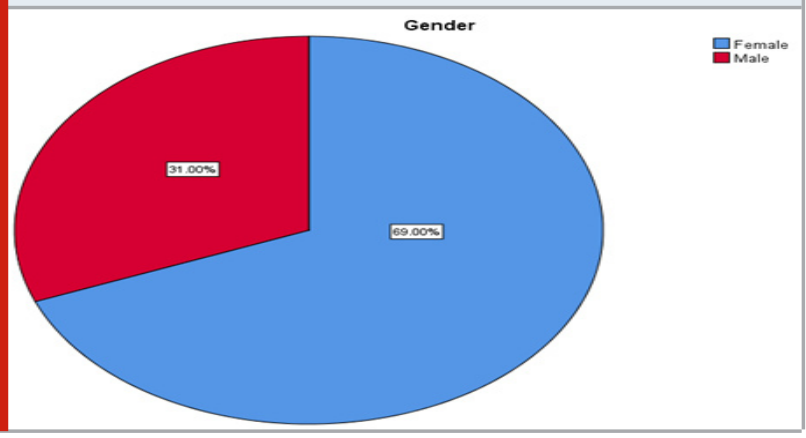

Figure 3: Pie chart representing that $86 \%$ of the respondents reported that obesity is a risk factor to diabetes (Red) whereas the rest 14\% have reported the opposite (Blue).

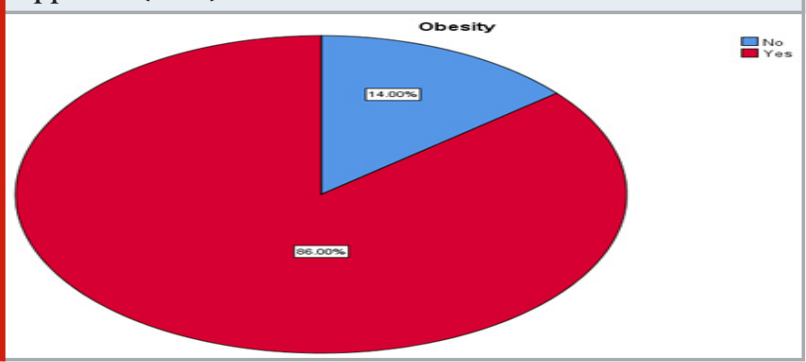

Figure 4: Pie chart representing that $30 \%$ of the respondents reported that pancreatitis is a risk factor to diabetes (Red) whereas the rest $70 \%$ have reported the opposite (Blue).

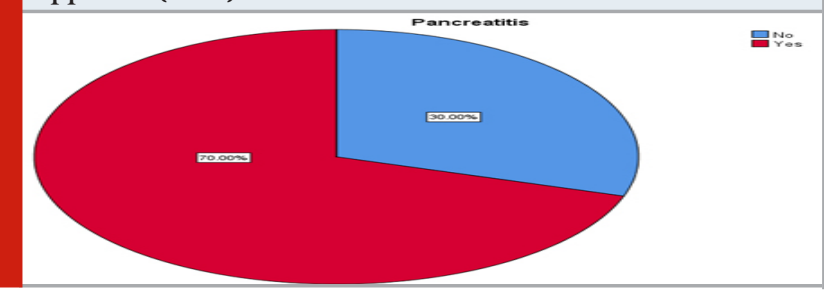


Figure 5: Pie chart representing that $68 \%$ of the respondents reported that age is a factor that predisposes to diabetes (Red) whereas the remaining 32\% have reported the opposite (Blue).

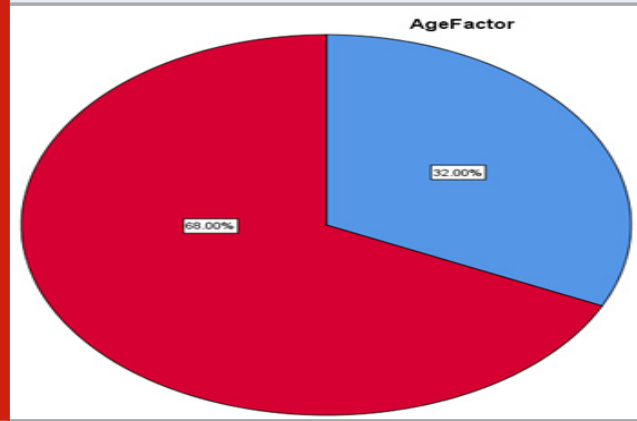

Figure 6: Pie chart representing that $61 \%$ of the respondents reported that polycystic ovarian disease in women increases the risk of diabetes (Red) whereas the remaining 39\% have reported the opposite (Blue).

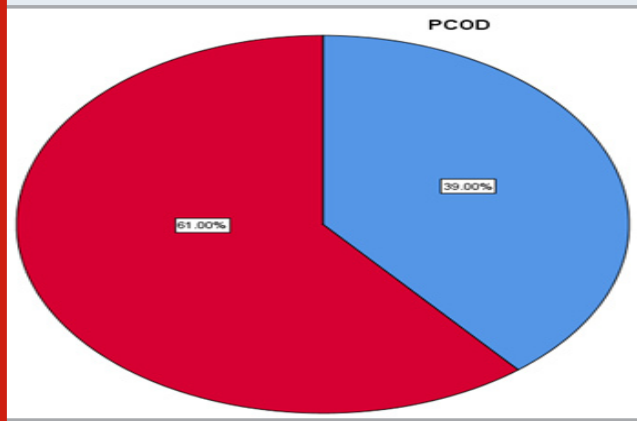

Figure 7: Pie chart representing that $79 \%$ of the respondents reported that hereditary is a factor of diabetes (Red) whereas the remaining 21\% have reported the opposite (Blue).

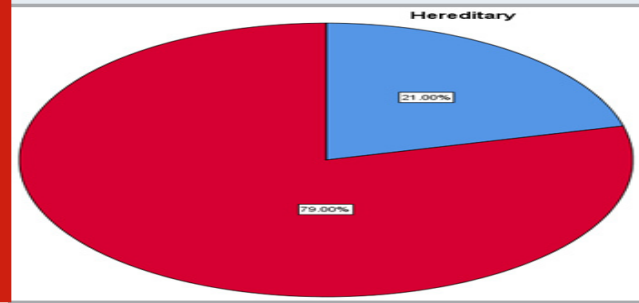

Figure 8: Pie chart representing that 59\% of the respondents reported that high blood pressure levels can lead to diabetes (Red) whereas the remaining $41 \%$ have reported the opposite (Blue).

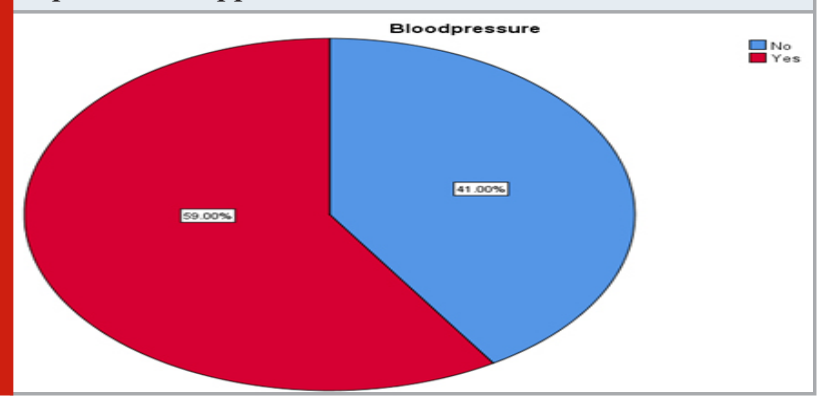

Figure 9: Pie chart representing that 79\% of the respondents reported that inactive lifestyle is a cause for diabetes (Red) whereas the remaining 21\% have reported the opposite (Blue).

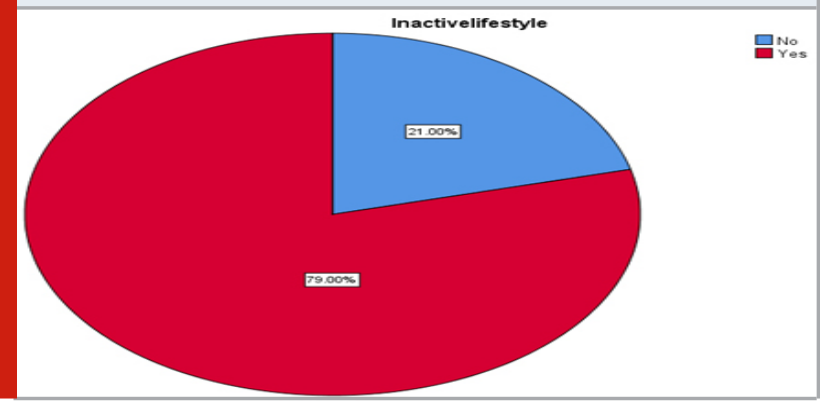

Figure 10: Pie chart representing that $68 \%$ of the respondents reported that smoking can increase the risk of diabetes (Red) whereas the remaining 32\% have reported the opposite (Blue).

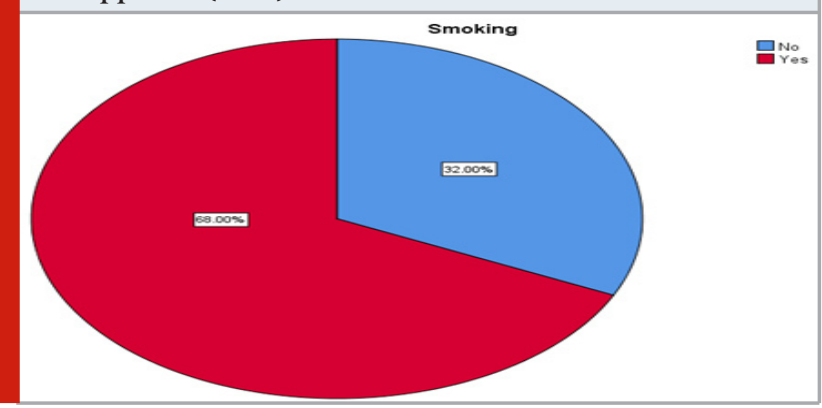

Figure 11: Pie chart representing that 59\% of the respondents reported that diabetes can lead to pancreatic cancer (Red) whereas the remaining $41 \%$ have reported the opposite (Blue).

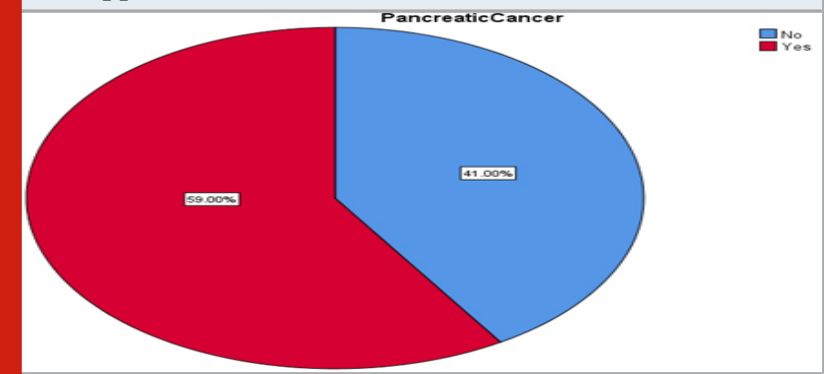

Figure 12: Pie chart representing that $66 \%$ of the respondents reported that high levels of triglycerides lead to diabetes (Red) whereas the remaining 34\% have reported the opposite (Blue).

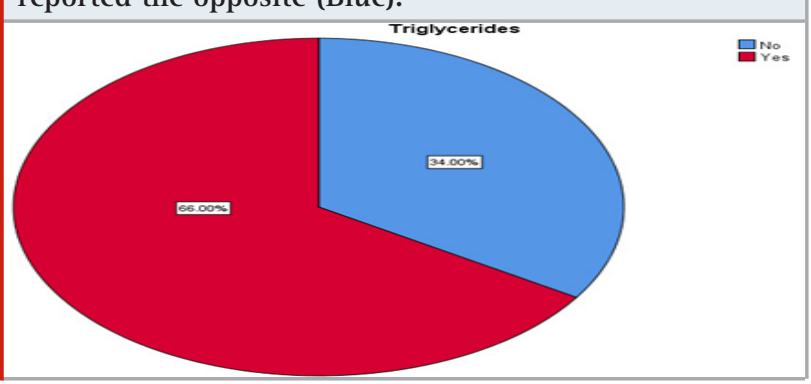


Figure 13: Pie chart representing that $60 \%$ of the respondents reported that gestation can cause diabetes (Red) whereas the remaining $40 \%$ have reported the opposite (Blue).

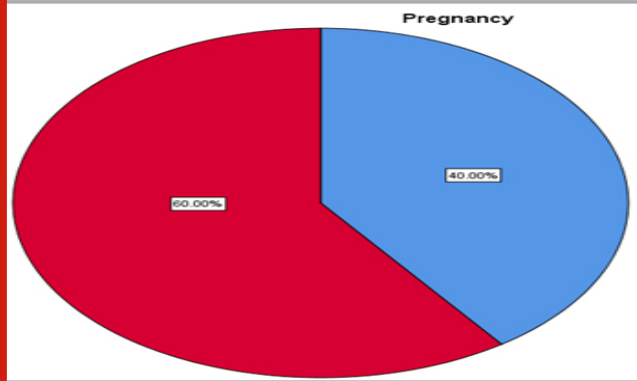

믄오

Figure 14: Pie chart representing that $77 \%$ of the respondents reported that cardiovascular disease can arise due to diabetes (Red) whereas the remaining 23\% have reported the opposite (Blue).

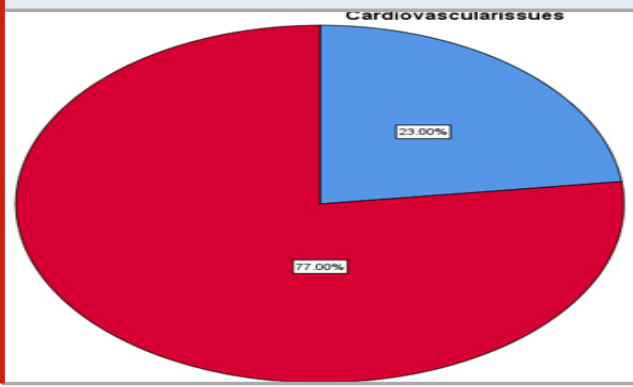

Figure 15: The bar graph demonstrates the association between the age group and the response of people towards the awareness of blood pressure being a predisposing factor to diabetes mellitus ( $\%$ responses). $\mathrm{X}$ axis represents the age group and $\mathrm{Y}$ axis represents the response of awareness of the people on blood pressure being a predisposing factor to diabetes mellitus (\% responses).Majority of the respondents between the age group 30-40 (27\%) have shown to be more aware in comparison to the age groups 40-50 (23\%) and 50-60(9\%). Chi square analysis was done, Pearson Chi square value $=4.891$, the $\mathrm{P}$ value is 0.087 ( $p>0.05)$, which is found to be statistically not significant.

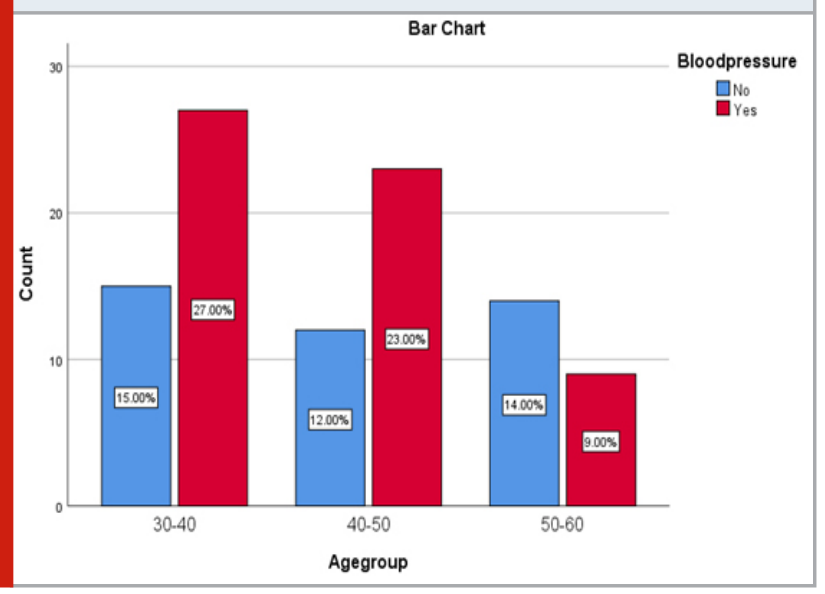

Figure 16: The bar graph demonstrates the association between the age group and the response of people towards the awareness of inactive lifestyle being a predisposing factor to diabetes mellitus ( $\%$ responses). $\mathrm{X}$ axis represents the age group and $\mathrm{Y}$ axis represents the response of awareness of the people on inactive lifestyle being a predisposing factor to diabetes mellitus ( $\%$ responses). Majority of the respondents between the age group 30$40(33 \%)$ have shown to be more aware in comparison to the age groups $40-50(28 \%)$ and $50-60(18 \%)$. Chi square analysis was done, Pearson Chi square value $=0.33$, the $\mathrm{P}$ value is 0.983 ( $p>0.05$ ), which is found to be statistically not significant.

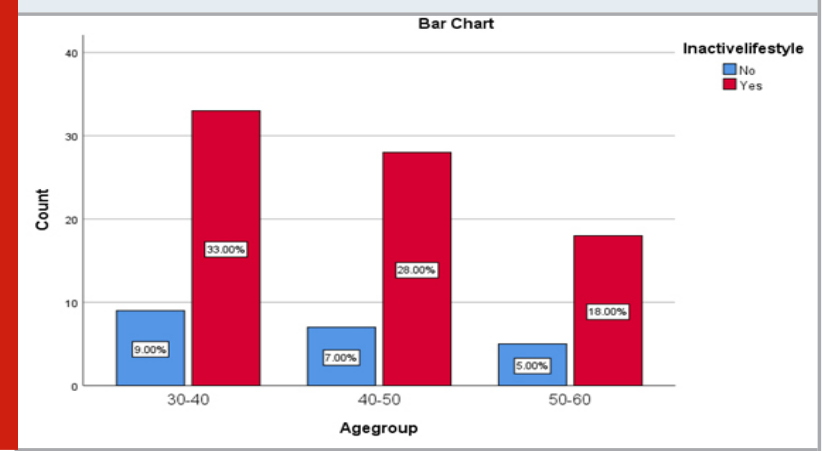

Figure 17: The bar graph demonstrates the association between the age group and the response of people towards the awareness of smoking being a predisposing factor to diabetes mellitus ( $\%$ responses). $\mathrm{X}$ axis represents the age group and $\mathrm{Y}$ axis represents the response of awareness of the people on smoking being a predisposing factor to diabetes mellitus ( $\%$ responses).Majority of the respondents between the age group 40-50 (27\%) have shown to be more aware in comparison to the age groups 30-40 (26\%) and 50-60(15\%). Chi square analysis was done, Pearson Chi square value $=2.143$, the $P$ value is $0.342(p>0.05)$, which is found to be statistically not significant.

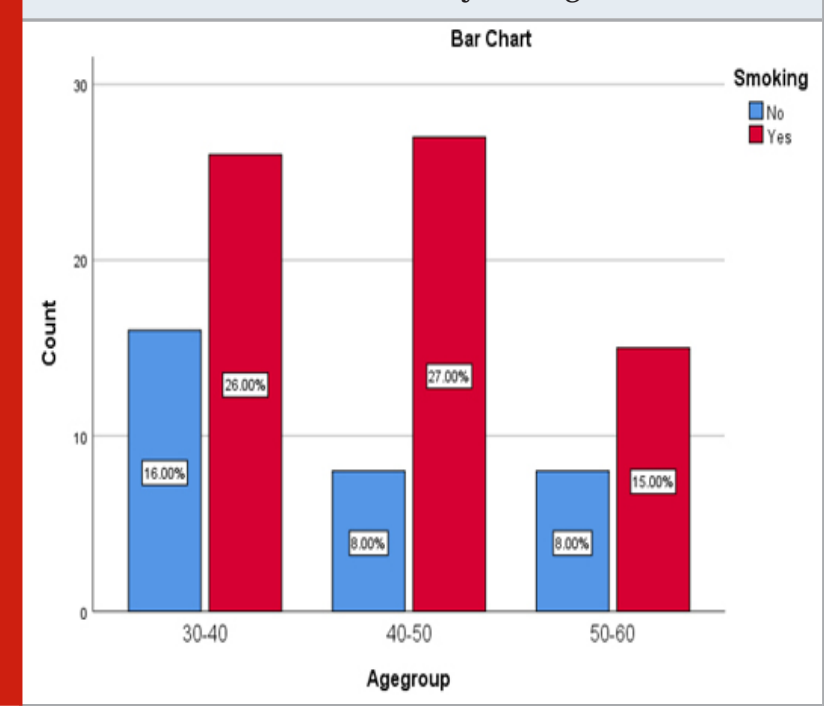


Figure 18: The bar graph demonstrates the association between the age group and the response of people towards the awareness of age being a predisposing factor to diabetes mellitus (\% responses). $\mathrm{X}$ axis represents the age group and $\mathrm{Y}$ axis represents the response of awareness of the people on age being a predisposing factor to diabetes mellitus (\% responses).Majority of the respondents between the age group 30-40 (34\%) have shown to be more aware in comparison to the age groups 40-50 (20\%) and 50-60(14\%). Chi square analysis was done, Pearson Chi square value $=5.672$, the $P$ value is $0.59(p>0.05)$, which is found to be statistically not significant.

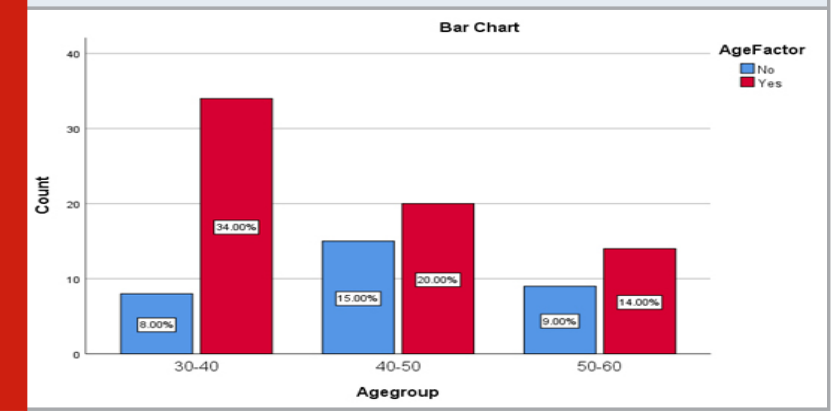

Figure 19: The bar graph demonstrates the association between the age group and the response of people towards the awareness of obesity being a predisposing factor to diabetes mellitus (\% responses). $\mathrm{X}$ axis represents the age group and $\mathrm{Y}$ axis represents the response of awareness of the people on obesity being a predisposing factor to diabetes mellitus (\% responses).Majority of the respondents between the age group 30-40 (37\%) have shown to be more aware in comparison to the age groups 40-50 (29\%) and 50-60 (20\%). Chi square analysis was done, Pearson Chi square value $=0.458$, the $P$ value is $0.795(p>0.05)$, which is found to be statistically not significant.

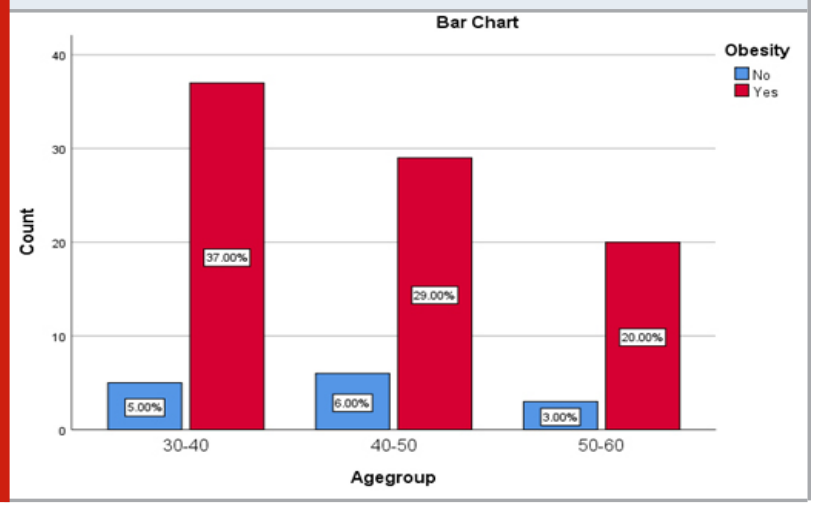

\section{CONCLUSION}

The results of this study demonstrated that there is significant knowledge on predisposing factors to diabetes mellitus among the general public.In risk patients with diabetes, all the predisposing factors have equal contribution to the disease with obesity, lifestyle and hereditary being the most common causes.
Diabetes mellitus comes with other associated disorders and therefore the control of diabetes is essential. This control can mainly be brought about only by the people themselves. Therefore, awareness on the same is very important.

\section{ACKNOWLEDGEMENTS}

We thank Saveetha dental college for the support to carry out this study.

Conflict of Interest: None to declare

\section{REFERENCES}

Accordino, M. K. et al. (2020) 'Incidence and Predictors of Diabetes Mellitus after a Diagnosis of Early-Stage Breast Cancer in the Elderly Using Real-World Data', Breast cancer research and treatment. doi: 10.1007/ s10549-020-05756-6.

Amor, A. J. et al. (2020) 'Different nuclear magnetic resonance lipoprotein profiles are associated with carotid atherosclerosis in type 1 diabetes and preeclampsia', Diabetes/metabolism research and reviews, p. e3362.

Asfandiyarova, N. S. (2015) 'A review of mortality in type 2 diabetes mellitus', Diabetes mellitus, pp. 12-21. doi: $10.14341 /$ dm6846.

Association, A. D. and American Diabetes Association (2007) 'Diagnosis and Classification of Diabetes Mellitus', Diabetes Care, pp. S42-S47. doi: 10.2337/ dc07-s042.

Aynalem, S. B. and Zeleke, A. J. (2018) 'Prevalence of Diabetes Mellitus and Its Risk Factors among Individuals Aged 15 Years and Above in Mizan-Aman Town, Southwest Ethiopia, 2016: A Cross Sectional Study', International Journal of Endocrinology, pp. 1-7. doi: 10.1155/2018/9317987.

Buell, C., Kermah, D. and Davidson, M. B. (2007) 'Utility of A1C for Diabetes Screening in the 19992004 NHANES Population', Diabetes Care, pp. 2233-2235. doi: 10.2337/dc07-0585.

Daousi, C. (2006) 'Prevalence of obesity in type 2 diabetes in secondary care: association with cardiovascular risk factors', Postgraduate Medical Journal, pp. 280-284. doi: 10.1136/pmj.2005.039032.

Deshpande, A. D., Harris-Hayes, M. and Schootman, M. (2008) 'Epidemiology of Diabetes and Diabetes-Related Complications', Physical Therapy, pp. 1254-1264. doi: 10.2522/ptj.20080020.

Finucane, P. and Popplewell, P. (no date) 'Diabetes Mellitus and Impaired Glucose Regulation in Old Age: The Scale of the Problem', Diabetes in Old Age, pp. 1-16. doi: 10.1002/0470842326.ch1.

Hales, C. N., Nicholas Hales, C. and Barker, D. J. P. (2001) 'The thrifty phenotype hypothesis', British Medical Bulletin, pp. 5-20. doi: 10.1093/bmb/60.1.5. 
John F. Maher, MD, FACP, FRCP(I) 1929-1992' (1993) Nephrology Dialysis Transplantation. doi: 10.1093/ ndt/8.9.791.

Kharroubi, A. T. (2015) 'Diabetes mellitus: The epidemic of the century', World Journal of Diabetes, p. 850. doi: 10.4239/wjd.v6.i6.850.

Kyvik, K. O. and Green, A. (2008) ‘Genetic Epidemiology of Type 1 Diabetes Mellitus', The Epidemiology of Diabetes Mellitus, pp. 403-412. doi: 10.1002/9780470779750. ch26.

Mercaldo, F., Nardone, V. and Santone, A. (2017) 'Diabetes Mellitus Affected Patients Classification and Diagnosis through Machine Learning Techniques', Procedia Computer Science, pp. 2519-2528. doi: 10.1016/j.procs.2017.08.193.
Olefsky, J. M. (2001) 'Prospects for Research in Diabetes Mellitus', JAMA, p. 628. doi: 10.1001/jama.285.5.628. Williams, B. (2011) 'Hypertension in diabetes mellitus', Oxford Textbook of Endocrinology and Diabetes, pp. 19691975. doi: 10.1093/med/9780199235292.003.1555.

Yari, Z. et al. (2020) 'Effects of soy isoflavones on serum lipids and lipoprotein (a) in peritoneal dialysis patients', Nutrition, metabolism, and cardiovascular diseases: NMCD. doi: 10.1016/j.numecd.2020.04.023.

Zubkova, N. A. et al. (2019) 'Erratum: a synonymous variant in GCK gene as a cause of gestational diabetes mellitus (diabetes mellitus. 2019;22(2). Doi: 10.14341/ dm9938)', Diabetes mellitus, pp. 405-406. doi: 10.14341/ dm11358. 